\title{
ATIVIDADE DOMÉSTICA E SOCIALIZAÇÃO - A VISÃO DE ADOLESCENTES DE CLASSES ECONOMICAMENTE DISTINTAS
}

\author{
DOMESTIC ACTIVITY AND SOCIALIZATION: THE VIEWPOINT OF \\ ADOLESCENTS FROM DIFFERENT SOCIOECONOMIC CLASSES
}

\author{
Mayara Barbosa Sindeaux Lima* \\ Fernando Augusto Ramos Pontes** \\ Simone Souza da Costa Silva*** \\ Júlia Bucher Maluschke ${ }^{+}$ \\ Celina Maria Colino Magalhães ${ }^{++}$ \\ Lília Iêda Chaves Cavalcante ${ }^{+++}$
}

Lima, MBS, Pontes, Silva SSdaC, Maluschke JB, Magalhães CMC, Cavalcante LIC. Atividade Doméstica e Socialização - a Visão de Adolescentes de Classes Economicamente Distintas. Rev Bras Crescimento Desenvol Hum. 2008; 18(2): 189-200.

\begin{abstract}
Resumo: A rotina familiar desempenha papel fundamental na socialização e é parte constituinte da cultura íntima da família. Dentre as atividades de rotina, a tarefa doméstica (TD) tem sido apontada como uma das estratégias para investigar tópicos centrais do desenvolvimento humano. Assim, o estudo dos sentidos atrelados a esta atividade pode fornecer indicativos dos processos de socialização. O objetivo desta pesquisa foi conhecer e discutir a visão dos adolescentes de classes economicamente distintas acerca dessa atividade. Participaram dois grupos de adolescentes com idade de 12 a 15 anos, o primeiro caracterizado como baixa renda (GBR), composto por dez participantes, sendo cinco de cada sexo; e o segundo como classe média (GCM), do qual fizeram parte onze adolescentes, três meninas e oito meninos. Os instrumentos utilizados foram: um questionário sócio-demográfico e um roteiro de entrevista semi-estruturado, sendo os dados coletados por meio de dois Grupos Focais. Nos resultados foi identificado que os grupos apresentaram temáticas similares, tais como, diferenciação de gênero, democracia doméstica e aquisição de habilidades. Contudo os sentidos construídos pelo GBR e o GCM acerca das TDs foram em sua maioria diferentes, pois o GBR deu maior ênfase à participação na tarefa doméstica como promotora de sobrevivência familiar e oportunidades desenvolvimentais.
\end{abstract}

Palavras-chave: socialização; adolescentes; tarefas domésticas; classe econômica.

\section{INTRODUÇÃO}

As investigações acerca do processo de socialização humana têm recebido contribuições de diferentes modelos teóricos. Dentre estes, destaca-se o de Bronfenbrenner ${ }^{1}$, onde o processo de aquisição dos padrões, valores e conhecimentos de uma sociedade está diretamen-

\footnotetext{
Bacharel em Psicologia pela UFPA. Endereço: Tv. Humaitá, No 2284, bairro: Marco, CEP: 66.093-110.

E-mail: mayarasindeaux@yahoo.com.br

** Doutor em Psicologia Experimental (USP), professor da Universidade Federal do Pará e pesquisador bolsista do CNPq.

*** Doutora em Psicologia (UNB), professora da UFPA.

+ Pós-doutora em Psicologia pela St. Johns University-EUA.

++ Doutora em Psicologia Experimental (USP), Professor da Universidade Federal do Pará. Pesquisador bolsista do CNPq.

${ }^{+++}$Doutoranda pelo Programa de Teoria e Pesquisa do Comportamento (UFPA), professora da UFPA.

Pesquisa vinculada ao Departamento de Psicologia Experimental da Universidade Federal do Pará- UFPA e parcialmente financiada pelo PIBIC/CNPq.
} 
te ligado às relações estabelecidas entre as pessoas e seus papéis em um dado contexto. Neste sentido, as interações que se dão entre os membros familiares são fundamentais para o processo de inserção da criança na sociedade.

Na perspectiva sistêmica de Bronfenbrenner ${ }^{1}$, a família é um microssistema onde ocorrem as principais relações face-a-face e se experimenta um padrão de atividades e papéis. Este é um contexto privilegiado de desenvolvimento que mantém relação de interdependência com os demais sistemas, a saber: meso, exo, e macro.

A noção de interdependência entre família e os outros contextos é compatível com o conceito de cultura íntima familiar de Serpell, Sonnenschein, Baker e Ganapath ${ }^{2}$. Eles consideram que a partir da cultura mais ampla a família produz um modo particular de cada um dos seus membros (e ela própria) se inserirem no mundo e avaliarem suas experiências. Desta maneira, à medida que as culturas íntimas das famílias diferem umas das outras, seus processos de socialização também se configuram de formas variadas.

As relações de interdependência da família com seus próprios membros e com os demais contextos são concretizadas nas rotinas e nos rituais. Conhecer as atividades cotidianas, e os sentidos construídos a partir delas, nos auxilia a refletir acerca dos processos de socialização, particularmente em famílias que ocupam espaços socialmente distintos. ${ }^{3,4}$ Dentre as atividades, a doméstica pode ser compreendida como o exercício de tarefas no âmbito doméstico, realizado pelos membros familiares para o benefício da própria família, sem que haja remuneração para isto ${ }^{5}$.

Além de ser um indicador acerca do contexto social onde as famílias estão inseridas, a atividade doméstica pode oferecer indícios do próprio contexto familiar. Segundo Moura ${ }^{6}$, a socialização das tarefas domésticas é um aspecto importante na sustentação da convivência da família. Pois a freqüência e a intensidade com que as tarefas da família tomam o caráter de "atividades em comum" sugerem um grau de colaboração, reciprocidade e interdependência entre os seus membros. Isto possibilita a atividade doméstica ser uma via de transmissão de valores e expressão de sentimentos ${ }^{5}$.
As regras familiares sobre as atividades domésticas propiciam às crianças/adolescentes uma orientação sobre o seu contexto sócio-cultural. Quando observam ou são envolvidas nas atividades domésticas, elas apreendem papéis de gênero, o que é apropriado à sua faixa etária e qual status social sua idade representa, além de experienciarem os modos particulares de organização familiar. Desta forma, a prática parental de atribuição de tarefas no lar tem sido associada na literatura a estratégias de socialização ${ }^{7}$.

A distribuição das tarefas doméstica aos filhos segue geralmente os critérios de: gênero, habilidades exigidas pela tarefa, as quais são orientadas pelo que se considera apropriado à idade, a ordem de nascimento e as necessidades dos pais ${ }^{8}$, 9,10 . O critério de gênero, além de ser o mais determinante, parece ser uma estratégia de divisão mais fácil e, para as crianças, pode ser um direcionamento que elas próprias preferem se estes sugerem um sinal de status no mundo adulto ${ }^{11}$.

Segundo Coltrane ${ }^{12}$, o desempenho diferenciado de meninos e meninas nas tarefas domésticas, leva-os a ter experiências e concepções divergentes sobre as mesmas. Em geral, estas são de responsabilidade das esposas e filhas, sendo a participação masculina compreendida como opcional. Assim, a forma como a atividade doméstica é experimentada durante a socialização infantil, provavelmente determinará a maneira que ela será vivenciada na vida adulta. Isto pode ser exemplificado no estudo de Gupta $^{13}$, no qual se verificou que os homens casados que despenderam mais tempo na atividade doméstica foram aqueles que a tinham realizado durante a infância.

Cohen $(2001)^{14}$ ao estudar a contribuição dos filhos nas tarefas do lar, investigou crianças de uma vila no sul da Índia, de uma cidade norueguesa e de uma canadense. Os dados indicaram que as crianças indianas foram as que mais realizaram tarefas domésticas; além disso, o fator gênero foi mais determinante na divisão de tarefas desta cultura do que nas demais. A autora explica as diferenças entre os países pelo grau de industrialização e urbanização dos contextos pesquisados, já que o trabalho das crianças na vila indiana é essencial em termos econômicos à 
sobrevivência da família.

Bastos $^{5}$ apresenta quatro grupos de justificativas parentais para atribuição das tarefas domésticas aos filhos. O primeiro se refere ao valor desenvolvimental das tarefas, principalmente o desenvolvimento da responsabilidade, além da promoção de múltiplas habilidades e habituação/valorização do trabalho. O segundo corresponde à democracia doméstica, onde cada membro da família assume alguma responsabilidade em benefício do grupo. O terceiro diz respeito à necessidade dos pais, pois existe a impossibilidade deles executarem as tarefas. E por último, o controle social, cujo objetivo é a restrição do tempo ocioso e ao acesso à rua.

No que diz respeito aos adolescentes, Bowes, Chalmers e Flanagan ${ }^{15}$ realizaram uma investigação com 500 adolescentes e jovens de 11 a 23 anos, residentes em três países do leste europeu (ex-comunistas) e três países ocidentais capitalistas. Os dados apontaram a responsabilidade como o principal valor das tarefas domésticas, independente do sexo e do país. Entretanto, as meninas mostraram mais comprometimento social do que os meninos, pois enfatizaram a responsabilidade ao grupo em detrimento da individual. Em relação às diferenças entre os países, aqueles caracterizados como individualistas foram os que mais ressaltaram as tarefas de auto cuidado e a responsabilidade individual.

A avaliação das implicações de curto ou longo prazo dos adolescentes sobre a atividade doméstica está permeada pelas formas como as famílias de classes diferentes organizam suas atividades diárias. Para determinadas famílias, a tarefa doméstica realizada por seus membros mais jovens adquire um papel fundamental na manutenção da unidade de sobrevivência do grupo. Deste modo, a pressão de socialização via tarefa e as percepções construídas a partir dela poderão variar em função da relativa importância dada pelos membros do grupo familiar a ela.

Considerando a associação existente entre as cognições e as práticas ${ }^{16,17}$, o estudo sobre os sentidos que os adolescentes têm em torno da atividade doméstica e dos aspectos relacionais envolvidos pode contribuir para a compreensão do seu processo de socialização. Neste sentido, a atividade doméstica é um palco privilegiado de investigação de várias temáticas do desenvolvimento humano, como as relações familiares, as questões de gênero, a aquisição de responsabilidade e a transmissão de valores.

O objetivo desta investigação foi conhecer e discutir a visão dos adolescentes de classes economicamente distintas acerca da atividade doméstica e do seu envolvimento nestas.

\section{MÉTODO}

\section{Participantes}

Participaram dois grupos de adolescentes sendo um de baixa renda e um de classe média, com idade de 12 a 15 anos e residentes na cidade de Belém-PA. Foram convidados a participar 12 adolescentes de cada grupo, pois de acordo com a literatura este é o número máximo de participantes para um Grupo Focal (GF). Contudo, nem todos compareceram ao local da entrevista.

O grupo de baixa renda foi composto por cinco adolescentes de cada sexo, cujas famílias tinham renda per capita inferior a meio salário mínimo. Participaram do grupo de classe média três meninas e oito meninos cujas famílias apresentavam renda per capita acima de dois salários mínimos.

\section{Instrumentos}

Foram utilizados um questionário sócio-demográfico e um roteiro semi-estruturado para condução do grupo focal. O questionário continha os seguintes itens: nome, idade e escolaridade de todos os membros familiares que residiam com o participante. Os temas que constituíram o roteiro semi-estruturado do GF foram: o que os adolescentes entendem por tarefa doméstica; qual a dinâmica de organização das atividades domésticas em suas famílias, como os participantes se posicionam diante desta divisão; como eles estão inseridos nas atividades caseiras e as relações que são estabelecidas por meio desta prática; quais são as repercussões em longo prazo da realização de TDs, quais são os valores, as crenças e sentimentos relativos as TDs. 


\section{Procedimento}

Esta pesquisa foi realizada de acordo com as considerações éticas presentes na resolução 196 do CONEP; sendo o número de aprovação do Comitê de Ética do Hospital João de Barros Barreto 2969-05. Aos adolescentes contactados e aos seus respectivos pais/responsáveis, se informava a finalidade da pesquisa, o procedimento a ser utilizado, a garantia do sigilo de identidades e a duração do grupo focal (GF). Entregava-se então o termo de consentimento livre e esclarecido aos tutelares e pedia-se aos que concordassem o assinarem.

A coleta de dados dos participantes de baixa renda ocorreu em uma das salas de uma creche situada próximo às residências deles, e dos de classe média em uma sala da escola particular em que estudavam. Os dados foram obtidos por meio de dois grupos focais, sendo um com o grupo de baixa renda (GBR) e o outro com o de classe média (GCM).

Durante esse procedimento havia pelo menos dois pesquisadores, um deles registrava as interações entre os participantes e os comportamentos não-verbais, enquanto o outro era o facilitador do GF, pois conduzia a discussão do grupo à temática da pesquisa e incentivava a participação dos adolescentes. As sessões de GF, cuja duração média foi de uma hora e meia, foram áudio-gravadas em fitas cassete, cuja duração foi em média de uma hora e meia.

Os dados foram analisados por meio da análise de conteúdo, segundo as etapas descritas por Bardinææ ${ }^{18}$ e Mianyo ${ }^{19}$, a saber: 1) pré-análise: retomada das hipóteses e dos objetivos iniciais da pesquisa, transcrição das narrativas, leitura exaustiva das mesmas e formulação de pressupostos iniciais; 2) exploração do material: os dados brutos são codificados para se alcançar o núcleo de compreensão do texto, o que ocorre por meio de triagem, contagem, e agrupamento das unidades de sentido; 3) tratamento dos resultados obtidos e interpretação: as categorias são criadas e discutidas de acordo com o quadro teórico, os objetivos da pesquisa e as dimensões que emergiram durante a coleta de dados e nas etapas anteriores.
A partir da análise dos dados foram detectadas duas dimensões. A primeira se refere aos sentidos e às implicações da atividade doméstica em nível imediato, composta pelas seguintes sub-unidades: "A execução da atividade doméstica", "Sobrevivência familiar e a democracia doméstica", "A mãe e o pai como referência na prática da atividade doméstica" e "As relações fraternais". A segunda dimensão corresponde às percepções da funcionalidade desta atividade ao longo do desenvolvimento, divididas em: "Desenvolvimento de habilidades e aquisição de responsabilidade", "Socialização para e pelo trabalho" e "A transmissão de valores".

\section{RESULTADOS E DISCUSSÃO}

A participação dos adolescentes do GBR e do GCM diferiu em função dos tópicos de discussão apresentados durante os GFs, o que justifica a apresentação de um número desigual de falas. Acrescido a isto, as verbalizações que se seguem apresentam em sua maioria caráter ilustrativo dos resultados obtidos, tendo em vista a inviabilidade de pontuar todos os dados em um artigo. Em relação às questões de gênero, ressalta-se que estas foram recorrentes em todos os momentos do grupo focal, e deste modo, a sua discussão será apresentada no decorrer das categorias.

No geral, percebeu-se que os adolescentes do GBR, quando comparados com o de GCM, apresentaram maior diversidade de sentidos e maior envolvimento na execução de tarefas domésticas (TDs) em seus lares. Este dado foi posteriormente evidenciado em uma pesquisa de natureza quantitativa feita com os mesmos participantes. ${ }^{20}$

\section{1- A atividade doméstica: os sentidos, as relações e as implicações imediatas}

\section{a) A execução da atividade doméstica}

A maioria dos participantes, independente do perfil econômico e do sexo, significou a realização de tarefa doméstica como pouco prazerosa, estereotipada e restritiva ao tempo livre. Como 
se observa nesta fala: “(...) tarefa doméstica todo mundo tem que fazer pelo menos uma vez na vida, mas não é legal, (...), no fundo, queria tá vendo TV, deitada (...)" (F1CM).

Embora os adolescentes de ambos os grupos sociais tenham percebido de maneira similar o tempo despendido nas tarefas caseiras, a freqüência e a qualidade do envolvimento nestas foram distintas. $\mathrm{O}$ que resulta em idéias diferentes acerca das implicações imediatas e de longo prazo.

A maioria dos adolescentes do GCM tem uma participação esporádica na atividade doméstica, realizando-a em alguns domingos/feriados ou em auxílio a alguém. Como pode ser ilustrado nesta verbalização: "Lá em casa, fica tudo arrumado que a empregada arruma tudo sábado. Aí só faz arrumar o que a gente sujou (...)" (M7CM). Alguns meninos ainda verbalizaram que não fazem essa atividade nem pretendem realizá-las futuramente.

Apesar dos adolescentes considerarem a atividade doméstica maçante, suas falas também indicam a necessidade de realizá-la, apontam-na como uma forma de controle social e de referência da unidade familiar. Segundo os participantes de ambos os sexos e grupos sociais, é necessário manter o ambiente doméstico limpo e organizado para a família não ser alvo de má impressão, como mostram as falas a seguir:

"O bom é que se chegar uma pessoa, tá tudo arrumado (...) se tivesse bagunçado a pessoa ia pensar: 'aqui eles não fazem nada', aí ia começar a pegar mal. (M2BR).

"... se eu for morar sozinho e não saber fazer nada, vai virar uma bagunça a casa, aí quando alguém for visitar vai falar que tá uma bagunça” (M3CM).

Contudo, o GBR ressaltou diferencialmente a questão do asseio em comparação ao GCM. $\mathrm{O}$ maior envolvimento na tarefa pode indicar que o estado da residência possa ser parte da sua percepção da unidade familiar. Desta forma, as impressões que a casa apresenta indicam o que este grupo é. Assim, a limpeza e organização parecem ser mais do que simplesmente medidas de saúde.

Acrescido a isto, os participantes do GBR entenderam o envolvimento nas tarefas domésticas (TDs) como promotor de outros benefícios de curto prazo. Dentre eles, o favorecimento de uma maior permanência em casa, onde se está protegido da violência da rua, do fácil acesso às drogas e às más companhias. Bastos ${ }^{23}$, ao estudar a socialização em famílias de baixa renda, encontrou resultados similares no relato de pais; estes acreditam que o engajamento nas tarefas caseiras é uma alternativa à permanência da criança na rua, espaço entendido por eles como pernicioso.

Levando em consideração a comunidade em que os participantes de baixa renda moravam (uma região de periferia desprovida de saneamento básico e com alto índice de criminalidade) a casa pode se tornar um refúgio natural contra a violência ocorrendo assim, uma associação entre a atividade e o local em que esta é realizada. Isto pode gerar uma polarização de sentimentos: rua - insegurança e casa - segurança. A fala abaixo apresenta vestígios desta associação e das possíveis conseqüências:

“ (...) [irmão] fala que eu sou mulher, porque eu faço as coisas em casa (...). Ele [irmão] não faz nada em casa e vai pra rua (...) ficar em casa e me chama de mulher e se ficar na rua vão me chamar de ladrão (...) aí eu vou aprender o que ele aprende (...) ele vive no meio desses malandros" (M1BR).

Como podemos perceber, além da questão da violência, esta fala também se dirige ao tema gênero e mostra uma relação fraternal conflituosa. Ao mesmo tempo em que a atividade doméstica propicia ao adolescente se diferenciar "daqueles que ficam na rua" torna-o alvo de provocações, particularmente aquelas que colocam em dúvida sua masculinidade. Aqui parece haver duas visões a respeito das tarefas caseiras, a do participante que as executa e a do seu irmão para o qual estas são tarefas de mulher, o que sugere um conflito tanto entre os irmãos quanto do próprio adolescente. A discussão sobre as relações fraternais será retomada no item "C". 
Apesar da questão de gênero recursivamente voltar em discussão, foram registradas poucas falas pontuando que a atividade doméstica deva ser atribuída exclusivamente ao gênero feminino, das quais se apresentam: "Domingo só a mamãe que faz (...). Porque ela é a mulher da família (...). Eu nunca ouvi falar em dono de casa. (...)"(M1CM), e “(...) aí quando eu tiver dinheiro (...) eu já vou poder ter uma empregada, aí a mulher e a empregada ajudam lá em casa." (M2CM).

O discurso acima provocou uma reação crítica das meninas como ilustra esta verbalização: "Eu discordo dele (...) os homens eles também tem que fazer alguma coisa, isso é machismo do tempo do ronca, que só as mulheres trabalhavam." (F1CM). Pondera-se que a preponderância do discurso socialmente aceito, ou seja, a idéia de que as TDs são responsabilidade de ambos os gêneros, pode ter decorrido tanto por uma mudança na visão das tarefas do lar quanto por influência do sexo dos pesquisadores, já que todos eram do sexo feminino.

\section{b) Sobrevivência familiar e a democracia} doméstica

Devido à quantidade e a riqueza dos sentidos que envolvem a família e as TDs, estes foram organizados didaticamente em diversas categorias. Como explicita o título desta sessão aqui se focaliza a manutenção do grupo familiar. Enquanto as categorias "C " e "D" destacam o modo como os participantes percebem, respectivamente, o papel da mãe e do pai nas TDs e suas relações com os irmãos.

A atividade doméstica foi considerada necessária à sobrevivência da família pela maioria dos participantes de baixa renda, independente do sexo, e de alguns de classe média. Contudo isto foi mais ressaltado pelas meninas do GBR, já que a responsabilidade por essa atividade parece ser transferida "naturalmente" às filhas, principalmente para as mais velhas.

A idéia apresentada acima parece ser assimilada tanto pelos meninos quanto pelas meninas de baixa renda, como observado nesta fala: "Eu já acho que quem deveria fazer era a minha irmã mais velha, eles são mais velhos mesmos, tem que cuidar dos menores (...)". (M3BR). Este dado é compatível com a literatura que aponta uma maior concentração de meninas primogênitas nos cuidados da casa e dos irmãos, tanto com relação à regularidade quanto à iniciativa própria. ${ }^{5,21}$

As idéias dos adolescentes do GBR a respeito da sobrevivência familiar ora davam ênfase à contribuição ora à obrigação. A primeira corresponde à idéia de que é responsabilidade dos filhos cooperarem com os pais. Assim, esta seria a parte que lhes cabe na sobrevivência familiar, como exemplifica esta fala: "Eu faço lá em casa por que eu quero (...) eles [pais] já tem que trabalhar pra dá pra gente o pão de cada dia (...)” (M2BR). A segunda refere-se à percepção de que os cuidadores deveriam assumir esta função, porém como despendem muito tempo e esforço no trabalho, a única alternativa aos filhos é desempenhá-las. Esta idéia pode ser observada na seguinte fala: "quem deveria fazer eram os pais, né (...) mas eles não podem, aí a gente que tem que fazer no lugar deles". (F4BR).

Semelhante aos dados encontrados por Cohen ${ }^{14}$, a participação dos adolescentes de baixa renda nas tarefas domésticas, tal como das crianças na Vila Indiana, é necessária em termos financeiros à sobrevivência da família, pois favorece que ambos os pais trabalhem fora de casa.

Segundo Baumrind (citado por Goodnown ${ }^{22}$ ) nos "contratos" implícitos entre os membros familiares, os comportamentos de auxílio e obediência da criança seriam o contrapeso à sustentação promovida pelos pais. Goodnow ${ }^{22}$ denomina essa atribuição de deveres e responsabilidades entre os familiares de "democracia doméstica", na qual cada um deve e tem que colaborar de alguma maneira para o benefício coletivo.

Os dados encontrados sugerem que o modo como os adolescentes do GBR contribuem com as TDs está associado às suas percepções da história de vida dos pais. Saber que os genitores cresceram em circunstâncias difíceis levou-os a sentirem-se solidários aos seus sacrifícios, bem como ponderarem o que eles acredi- 
tam serem erros cometidos pelas figuras parentais. A valorização da trajetória pessoal dos pais pode favorecer o desenvolvimento de cumplicidade, propiciar um modelo a ser seguido, e consequentemente, uma maior identificação com o grupo familiar e um senso de pertencimento. As falas abaixo ilustram algumas observações feitas acima:

“(...) [mãe] diz que eu sou muito preguiçosa, mas eu não acho assim, eu faço tudo lá em casa (...) aí ela vem querer me bater (...) eu acho que a minha mãe faz assim porque ela sofreu (...) acho que ela quer ser um pouco revoltada (...)” ( $\mathrm{F5BR})$.

“(...) quando eles [pais] eram crianças eles passaram por tudo que a gente passou... ou pior, que nem o papai” (M3BR).

Em termos gerais, o tema sobrevivência familiar esteve ausente no relato dos participantes de classe média. É provável que isto se deva ao fato da maioria destes ter empregada doméstica, e para aqueles que não têm cabe à mãe a responsabilidade de executar as tarefas caseiras; isto os levou a se referirem à empregada doméstica com frequiência.

Entretanto, alguns participantes do GCM, particularmente as meninas, ressaltaram a importância de ajudar nas tarefas do lar mesmo quando há alguém contratado para realizá-las. Esta idéia foi encontrada também entre os adolescentes que diziam não fazer atividade doméstica. Embora nem sempre se configure como uma prática cotidiana, este discurso socialmente aceito sugere uma valorização da atividade doméstica para a vida familiar.

Nas verbalizações que se seguem podemos observar que alguns adolescentes do GCM acreditam que o auxílio nas TDs seja uma ação esperada de um "bom filho", além de fazerem referência à democracia doméstica:

"fica meio injusto só a mamãe fazer [TDs], a mamãe trabalha a semana inteira $e$ dia de domingo a mamãe tem os mesmos direitos que еu." (F1CM)

“(...) Eu, eu... ofereço ajuda naquela vontade quando eu vejo que a mamãe não quer minha ajuda (...) fingindo que eu tô ajudando" (M4CM).

c) A mãe e o pai como referência na prática da atividade doméstica

A forma como os adolescentes pesquisados se inserem na atividade doméstica e suas percepções sobre as TDs, também se entrelaçam com os significados desses a respeito dos papéis de pai e mãe. Em conseqüência disto, a forma como os adolescentes compreendem a relação dos pais com a atividade doméstica nos auxilia a entender a própria relação dos participantes com esta atividade.

Independente da classe social e do sexo, os dados confirmam a literatura ao considerar a mãe a principal referência das tarefas caseiras. A centralização na figura materna pode se constituir em um modelo de gênero comumente presente nas TDs. Além da maioria destas serem culturalmente consideradas femininas, levando a uma distribuição desigual entre os irmãos de sexos opostos, esta diferença estende-se aos cuidadores, sendo o pai menos mencionado pelos participantes.

Em relação ao pai, os temas levantados pelos participantes, de ambos os sexos e classes sociais, dão uma mostra da diversidade de papéis e padrões comportamentais pertinentes ao homem contemporâneo, já que as idéias apresentadas foram desde o pai provedor da família e distante do âmbito doméstico ao pai participativo nas questões caseiras, assumindo papel de co-responsável por elas.

O perfil de pai tradicional pode ser percebido em várias falas semelhantes a esta: “(...) a gente chama o papai pra lavar louça ele falou 'tem três mulher aqui em casa, porque vocês não fazem?' (...). Porque eu acho que ele se ofende de tá lavando louça (...) eu fico com raiva, dá vontade de pegar e dá um soco nele (...). A mulher se sente obrigada a fazer tudo." (F5BR). Já o perfil do pai contemporâneo pode ser identificado nesta fala: “...o papai é o único que trabalha fora (...). Mas ele sempre procura tá ajudando (...) pra não 
ficar sobrecarregando uma só pessoa. (...)" (F3CM).

Um aspecto interessante que foi verificado é a percepção do adolescente da associação do uso da atividade doméstica pelo pai como uma estratégia de garantir a integração familiar. Um dos participantes se referiu à prática paterna de tarefas caseiras como uma forma de apaziguamento com a mãe, como se observa em sua verbalização: "Meu pai quando faz alguma coisa [TDs] é porque ele e a minha mãe tão de briga (...)" (M4CM).

A literatura não apresenta dados consensuais acerca da participação masculina na atividade doméstica, de acordo com Weisner, Garnier e Loucky ${ }^{24}$, embora alguns estudiosos afirmem que ela aumentou a ponto de mudar a divisão de trabalho no lar, as pesquisas do uso do tempo indicam que a segregação ainda persiste. Segundo Coltrane ${ }^{12}$, apesar da maioria dos homens e mulheres concordar que o trabalho na família deve ser compartilhado, poucos homens assumem a responsabilidade pelas tarefas da casa.

\section{d) As relações fraternais}

As relações fraternais e a presença de conflitos entre os irmãos emergiram apenas no discurso dos participantes de baixa renda. Sendo que as meninas ressaltaram mais esta questão, pois acreditam que são sobrecarregadas em privilégio dos irmãos, vale ressaltar que a maioria destas adolescentes era primogênita. Neste sentido, o conflito parece depender principalmente da aceitação dos critérios de atribuição das tarefas da casa, cujos principais foram: o gênero e a ordem de nascimento. Estes critérios são compatíveis com aqueles apresentados na literatura. ${ }^{8}, 9,10$

O sentir-se sobrecarregado ou acreditar que desempenha funções demasiadas na família pareceu propiciar interações menos coesas tanto com os irmãos quanto em relação à pessoa que atribui as atividades. De acordo com Bastos $^{5}$, é necessário que os membros familiares sintam que a distribuição de responsabilidade e os esforços para o grupo sejam justos. Assim, a participação de todos os membros seria um im- portante aspecto para o equilíbrio familiar, como pode ser verificado nos trechos abaixo: "o meu irmão não faz nada lá em casa (...) aí eu vejo tudo desarrumado aí eu vou lá e arrumo, aí chega um [irmão] lá e desarruma. Aí eu fico com raiva. (...)" (M1BR).

\section{2- A atividade doméstica: os sentidos, as relações e as implicações em longo prazo}

a) Desenvolvimento de habilidades e aquisição de responsabilidade

A atividade doméstica foi considerada pelos adolescentes de baixa renda, de ambos os sexos, como favorável e natural às crianças. Já que promove benefícios de desenvolvimento próprios à infância e que serão extremamente necessários na vida adulta, como nos mostra essa fala: “(...) a gente tem que aprender desde cedo, (...) se não aprendeu na infância como é que vai aprender na idade adulta?" (M1BR). Tais observações indicam que as tarefas domésticas podem servir de mecanismo para a introjeção de valores; esta temática será tratada com mais detalhe no item " $\mathrm{C}$ ".

Um dado que confirma estas observações é que todos os participantes do sexo feminino e a maioria do masculino do GBR assimilam as tarefas como suas responsabilidades, o que é ilustrado nesta fala: “(...) a mamãe não manda porque eu já sei o que eu tenho que fazer, quando eu era pequena ela mandava, mas agora eu pego e faço" (F3BR). A responsabilidade parece ser o principal valor promovido pela atividade doméstica, e que é imprescindível para atingir uma das metas de socialização que é a de estar apto ao mercado de trabalho.

Para Bastos $^{23}$, a responsabilidade é um elemento central para o desenvolvimento do senso de pertencer à família, de modo que, ao responder às demandas familiares, a criança assume um novo status dentro do grupo, identificando-se com este e adotando os projetos coletivos como sendo seus.

Sobre a relação entre tarefa doméstica e a responsabilidade, Bowes, Chen, San e Yuan ${ }^{23}$ afirmam que o desenvolvimento da responsabili- 
dade é um dos objetivos dos pais em torno da atividade doméstica. Em conformidade com isto, em um estudo realizado com adolescentes de seis países se encontrou resultados semelhantes aos apresentados no presente estudo, pois a maioria dos adolescentes acredita que atividade doméstica tem valor desenvolvimental às crianças, sendo uma forma de incentivar a responsabilidade. $^{15}$

Os participantes do GCM apresentaram idéias heterogêneas no que diz respeito à relação entre as TDs e o desenvolvimento de habilidades/competências. Enquanto para alguns as TDs podem ser promotoras de responsabilidade, organização e autonomia; para outros, elas não oferecem quaisquer ganhos de desenvolvimento pois mantêm uma relação de descompromisso com a mesma. Estas observações são ilustradas nas falas a seguir:

"quando eu me formar, só que eu não vou ter dinheiro ainda, aí eu vou sair de casa e morar sozinho, aí eu vou ter que pelo menos arrumar casa (...)" (M3CM).

"Eu não faço nada que é a empregada que faz" (M3CM).

Apesar da similaridade entre algumas idéias presentes no GCM e no GBR sobre os benefícios da atividade doméstica, os sentidos que emergiram no último apresentam uma maior complexidade. Pois a maioria dos participantes de baixa renda acreditam que a prática de TDs é necessária à inserção no mercado de trabalho; que foi pouco referido pelos adolescentes do GCM. A sessão subseqüiente detalhará essa análise.

b) Socialização para e pelo trabalho

Apesar dos participantes do GBR expressarem que meninos e meninas devem realizar as TDs, a qualidade do envolvimento nesta atividade parece ser percebida por ambos como díspare, sendo a participação feminina maior. Esta aparente incongruência parece se originar nos objetivos e metas de desenvolvimento que os participantes acreditam ser apropriados para si e para o sexo oposto.
A funcionalidade da aprendizagem das TDs na vida adulta das meninas do GBR está diretamente ligada a uma fonte de renda, pois podem trabalhar como empregada doméstica, neste caso estas tarefas consistiriam em toda a sua atividade laboral. Enquanto para os meninos a relação com o emprego é indireta, já que as tarefas seriam uma via de desenvolver a capacidade de independência e organização.

Estas idéias quanto ao futuro emprego mostram que as diferenças de gênero presentes na atividade doméstica vão além das relações imediatas e chegam às expectativas profissionais. Enquanto os meninos parecem esperar um "bom emprego", como ilustra esta fala: "Já pensou eu advogado no meu escritório a mesa toda bagunçada lá? Eu vou ter que arrumar os papéis" (M1BR), as meninas parecem esperar apenas ter um trabalho: "Eu acho que vai servir [tarefas domésticas] (...) uma família passando necessidade, aí o único emprego que tem é de doméstica (...)" (F1BR).

No que diz respeito ao GCM, os adolescentes emitiram poucas verbalizações sobre o trabalho assalariado, particularmente relacionando-o com a prática de tarefas caseiras. Apenas houve uma participante que associou a atividade doméstica como uma habituação ao trabalho, como ilustra esta verbalização: "A gente tem que fazer [TD] (...) porque é uma coisa que a gente vai viver pro resto da vida, a gente que tem que começar a se acostumar... como um trabalho (...)" (F2CM).

Estes resultados vão ao encontro das idéias de Bastos $^{23}$, pois afirma que a educação por meio do trabalho parece ser uma estratégia apropriada às classes pobres. Pois a habituação precoce ao trabalho é a única garantia de se inserir na sociedade, mesmo que esta possa ser de uma forma excludente e marginalizante.

\section{c) A transmissão de valores}

Alguns adolescentes de classe média mostraram apreensão de valores por meio da atividade doméstica, referentes a papéis de gênero, habituação ao trabalho, e do auxílio a quem executa as tarefas caseiras, como mostra esta fala: 
"Eu acho que a minha mãe e o meu pai devem pensar que é pra todo mundo ajudar, porque... desde pequeno (...) me ensinaram que é pra sempre ajudar a pessoa que tá fazendo as coisas (...) dia de domingo sempre é tudo dividido, então a gente assim.. desde pequeno se acostumou com isso" (F1CM).

Em relação aos participantes de baixa, eles parecem valorizar as TDs como uma estratégia de socialização eficaz. Isto é confirmado quando estes assimilam alguns valores envoltos na atividade doméstica e acreditam que esta possa ser um meio de transmiti-los. Segundo os participantes de baixa renda, eles pretendem ensinar os seus filhos a fazerem TDs para que sejam autônomos, adquiram responsabilidade e habilidades necessárias à vida adulta, particularmente no que se refere ao trabalho. As falas a seguir ilustram as observações feitas acima:

"Quem faz [tarefa doméstica] vai aprender a ter juízo, e ver tudo que a gente passou pra puder chegar onde a gente tá, (...) aí ele [filho] vai querer fazer" (F2BR);

"Ele [futuro filho] vai saber ajeitar a casa dele e saber trabalhar... assim como a gente aprende as coisas de casa... a gente pode aprender várias coisas (...)”. (F1BR).

Segundo Porto e Tamayo ${ }^{26}$, a transmissão cultural é o resultado da transferência de informação que pode se dar por meio da observação, imitação e condicionamento, sendo responsável pela similaridade encontrada entre pais e filhos. Assim a transmissão cultural é um dos processos mantenedores da estabilidade entre as gerações presentes em uma família, e está particularmente relacionada à sua cultura íntima.

\section{CONSIDERAÇÕES FINAIS}

Os sentidos construídos acerca da atividade doméstica pelos adolescentes apresentaram marcos que parecem ser centrais, como o gênero e a classe econômica, esse aspecto se destaca ao observarmos que eles estiveram presentes nas diversas temáticas trazidas durante os grupos focais. A maioria dos temas evocados pelos dois grupos sócio-econômicos (baixa renda e classe média) tem relação entre si, tais como: as relações familiares, a democracia doméstica, a aquisição de autonomia e de responsabilidade, e as expectativas futuras.

A construção de sentidos relacionados à atividade doméstica depende da qualidade do envolvimento nas mesmas, o que inclui a iniciativa, a frequiência, os tipos de tarefas e a quem estas beneficiam. Considerando que os representantes do GBR desenvolvem mais TDs que os do GCM, supõe-se que suas percepções sejam possibilitadas por uma maior diversidade de relações e intensidade de questões por elas suscitadas. Assim, as percepções de uma prática e o próprio ato de fazê-la parecem constituir uma unidade para a compreensão da função e das implicações dessa à socialização.

No caso da atribuição das tarefas, a compreensão de que os critérios para a divisão são justos favorece a unidade tanto fraterna quanto parental, posto que o sentimento de sobrecarga e a carência de reconhecimento contribuem para um relacionamento familiar conflituoso. Entretanto, como já sinalizado acima, os adolescentes de baixa renda ressaltaram diferencialmente estas questões, pois destacaram sua participação na atividade doméstica como relevante à manutenção do grupo e à democracia familiar.

A constante referência às figuras parentais sugere que a atividade doméstica pode ser uma das estratégias de transmissão de valores da família, particularmente no que diz respeito ao sexo feminino. A percepção acerca da mãe foi marcada de forma determinante pela diferenciação de gênero em ambos os grupos. Já que esteve essencialmente atrelada ao âmbito doméstico, mesmo quando esta trabalha fora da residência. No que diz respeito ao pai, prevaleceu o entendimento de que ele é o provedor do lar, mas que deve auxiliar na realização das tarefas.

Pôde ser apreendido, a partir do discurso dos dois grupos sócio-econômicos, que estes vêem a prática das TDs como enfadonha e restritiva ao tempo livre. Porém, a maioria de seus participantes também percebeu ganhos advindos desta, particularmente a responsabilidade e organização. Apesar dessa aparente similaridade en- 
tre os grupos, ela se desfaz quando se observa a relevância que cada um dá a esta prática. O GBR parece compreender o envolvimento nas TDs como um dos principais promotores de oportunidades de desenvolvimento. Isto se torna explicito à medida que as associaram as habilidades/ competências de que serão exigidos para a inserção no mercado de trabalho.

Esta pesquisa apresentou indícios que podem auxiliar nas reflexões acerca da função da tarefa doméstica no processo de socialização, especialmente de adolescentes urbanos de classes distintas. Pois permitiu conhecer como os próprios adolescentes estão compreendendo sua participação nesta prática e as relações intrínse- cas a ela. Acrescido a isto, alerta a comunidade científica e a sociedade em geral que a discussão acerca do envolvimento de adolescentes nas TDs deve considerar o contexto em que estes estão inseridos, analisando quais são os ganhos e prejuízos ao desenvolvimento.

Uma continuidade às investigações deste âmbito deve ser a realização de pesquisas longitudinais, cujo foco seja a atividade doméstica e as relações, percepções e sentimentos a ela ligados em diferentes momentos do ciclo vital da pessoa na família. Pois se entende que as idéias referentes às implicações imediatas e em longo prazo podem se modificar em função do papel assumido no seio familiar.

\begin{abstract}
Family routine plays a fundamental role in socialization, and is an important feature of intimate family culture. Among the routine activities, the study of domestic tasks (DT) has been identified as a key strategy for investigating issues dealing with human development. Thus, meanings associated with DT may be used as indicators of certain socialization processes. The aim of this investigation was to identify and discuss the viewpoints of adolescents from different socioeconomic classes regarding DT. Two groups of adolescents aged between 12 and 15 years participated in the study: 10 adolescents (five of each sex) from lower-income families (LIF), and 11 (3 girls and 8 boys) from middle-income families (MIF). A socio-demographic questionnaire and a semi-structured interview were used, and data were collected through two Focal Groups. Both groups yielded similar themes, such as gender differentiation, domestic sharing, and skill acquisition. However, the DT meanings constructed by LIF adolescents differed from those constructed by MIF adolescents, because those from the former group tended to consider participation in the domestic task as important for family survival and developmental opportunities.
\end{abstract}

Keywords: Socialization; adolescents; domestic tasks; socioeconomic class.

\section{REFERÊNCIAS}

1. Bronfenbrenner, U. Ecology of the family as a context for human development: Research perspectives: Developmental Psychology. 1996; 22:723-742.

2. Serpell, R.; Sonnenschein, S.; Baker, L.; Ganapathy, H. Intimate Culture of Families in the Early Socialization of Literacy (Special Section: Family Routines and Rituals). Journal of Family Psychology. 2002; 16 (4): 91-405.

3. Boyce, W. T., Jensen, E. W., James, S. A. \& Peacock, J. L. The family routines inventory: Theoretical origins. Social Science and Medicine. 1983; 17 (4): 201-211.

4. Larson, R. W.; Richards, M. H.; Sim, B. \& Dworki, J. How Urban African American Young
Adolescents Spend Their Time: Timw Budgets for Locations, Activities, and Companionship. Americam Journaul of Community Psychology. 2001;29 (4): 565-593.

5. Bastos, A. C. S. Modos de partilhar: A criança e o cotidiano da família. Taubaté: Cabral Editora Universitária; 2001.

6. Moura, W. A família contra a rua: uma análise psicossociológica da dinâmica familiar em condições de pobreza. Em: A. Fausto \& Cervini (org.) Perspectivas futuras. O trabalho e a Rua: Crianças e adolescentes no Brasil urbano dos Anos 80. São Paulo: Cortez/UNICEF/FLACSO; 1991.p. 151-194.

7. Cohen, R. Children's contribution to household labour on three sociocultural contexts: A Southern Indian Village, a Norwegian town and 
a canadian City. International Journal of Comparative Sociology. 2001; 42 (4): 353-367.

8. Ferreira, E. A.P. \& Mettel, T. P. L. Interação entre irmãos em situação de cuidados formais. Psicologia Reflexão e Crítica. 1999; 12 (1): 133146.

9. McHale, S. E., Bartko, W. J.,Crouter, A. C., \& Perry-Jankins, M. Children's housework and psychosocial functioning: The mediating effects of parent's sex role behavior and attitudes. Children Developmental; 1990. 61: 1314-1326.

10. Shelton, A. B. The Division of Household Labor. Annu. Rev. Sociol; 1996. 22: 299-322.

11. Antill, J. K; Goodnown, J.J; Russel, G; Cotton, $S$. The influence of parents and family context on children's involvemnet in household task. Sex Roles: A Journal of Research. Fev. 1996; 34 (22): p.215-236.

12. Coltrane, S. Research. Household Labor: Modeling and Measuring the Social Embeddedness odf Routine Family Work. Journal of Marriage and the Family. 2000; 62: 1208-1233.

13. Gupta, S. The Consequences of Maternal Employment During Men's Childhood for their Adult Housework Performance. Gender Society. 2006; 20 (1): 60-86.

14. Cohen, R. Children's contribution to household labour on three sociocultural contexts: A Southern Indian Village, a Norwegian town and a canadian City. International Journal of Comparative Sociology. 2001; 42(4): 353-367.

15. Bowes, J. M., Chalmers, D. \& Flanagan, C. 'Children's involvement in household work: Views of adolescents in six countries'. Family Matters. 1997; 46: 26-30.

16. Blasi, A. Bridging moral cognition and moral action: A critical review of the literature. Em B. Puka, et al. (Orgs.). Fundamental research in moral development. 1994. p. 123-167. New York: Garland Publishing,

17. Rest, J. R. Moral development: Advances in research and theory. New York: Praeger, 1986.

18. Bardin, L. Análise de conteúdo. Lisboa: Edições 70; 1979.

19. Minayo, M. C. de S. O desafio do conhecimento: pesquisa qualitativa em saúde. 7. ed. São Paulo: Hucitec; 2000.

20. Lima, M. B. S \& Pontes, F. A. R. Tarefas domésticas e socialização na perspectiva de adolescentes de classe economicamente distintas. Revista científica da UFPA. [periódico online]. 2006. [acesso em 10 de novembro de 2007]. Disponível em.

21. Punch, S. Household Division of Labour: Generation, Gender, Age, Birth Order and Sibling Composition Work. Employment \& Society; 2001. 15 (4): 803-823.

22. Goodnown, J.J. Children's household Work: Its Nature and Functions. Psychological Bulletin; 1988. 103 (1): 5-26.

23. Bastos, A. C. S. O trabalho como estratégia de socialização na infância. Veritat; 2002.2 (2): 1938.

24. Weisner, T. S; Garnier, H; Loucky, J. Domestic tasks, gender egalitarian values and children's gender typing in conventional and nonconventional families. Sex Roles: A Journal of Research; 1994. 30: 23-54.

25. Bowes, J. M.; Chen, M.J; San L, Q. \& Yuan, L. Reasoning and negotiation about child responsibility in urban Chinese families: Reports from mothers, fathers and children. International Journal of Behavioral Developmen.t; 2004. 28 (1): 48-58.

26. Porto, J. \& Tamayo, A. Influência dos Valores Laborais dos Pais sobre os Valores Laborais dos Filhos. Psicologia: Reflexão \& Crítica; 2006. 19 (1): $151-158$. 